\title{
Numerical Simulation and Experimental Study on the Interface Bonding of Stainless Steel Clad Plate
}

\author{
H. R. Jin, ${ }^{\text {a,b }}$ L. Zhang, ${ }^{c}$ C. Dai, ${ }^{c}$ and Y. L. Yi ${ }^{c, 1}$ \\ ${ }^{a}$ Key Laboratory of Advanced Forging \& Stamping Technology and Science, Ministry of Education \\ of China, Yanshan University, Qinhuangdao, China \\ b Parallel Robot and Mechatronic System Laboratory of Hebei Province, Yanshan University, \\ Qinhuangdao, China \\ c School of Mechanical Engineering, Yanshan University, Qinhuangdao, China \\ ${ }^{1}$ yiyali@ysu.edu.cn
}

The rolling temperature and rate of thickness reduction directly affect the interface bonding quality, mechanical properties and microstructure of stainless steel clad plate. In order to obtain reasonable rolling process parameters, the multi-pass rolling processes of Q345R/316L stainless steel clad plate were simulated by the DEFORM software package. The distributions of stress, strain, and microstructure fields of the clad plate at different rolling temperatures and reduction rates were investigated. The bonding state of the interface was determined and the change rules governing the grain size of the rolled substrate layer also were analyzed. Vacuum hot-rolling tests were carried out to characterize the microstructure and mechanical properties. It was found that the higher the rolling temperature, the lower was the reduction rate needed to realize the interface bonding. However, too high temperatures produce a higher fraction of coarse grains, which affects the overall mechanical properties of the clad plate. It was concluded from the tests and numerical results that rolling temperature of $1150^{\circ} \mathrm{C}$ and reduction rate exceeding $50 \%$, stainless allow one to produce steel clad plates with high interface bonding quality and excellent microstructure.

Keywords: stainless steel clad plate, rolling temperature, reduction rate, interface bonding, mechanical properties.

Introduction. Hot-rolled stainless steel clad plates are produced by bonding of a stainless steel cladding layer to a low-alloy steel substrate layer [1-3]. Such plated are widely used in petrochemical, marine, nuclear power and other fields due to their high corrosion resistance and mechanical properties, as well as reduced cost,as compared to solid stainless plates. Suitable process parameters are necessary to get better interface bonding quality, which is a key factor for good mechanical properties of stainless steel clad plate. In order to select appropriate process parameters, the effects of the interface bond quality and the mechanical properties of the microstructure resulting from different rolling temperatures and reduction rates were investigated $[4,5]$.

Bimetallic composite rolling is a complex plastic forming process under the coupled effect of multiple factors that influence the internal microstructure and overall mechanical properties of the composite plate. The interaction between the elements of the composite plate interface is crucial to good mechanical properties of composite material. Investigation of the interfacial microstructure properties can help to reveal the inherent characteristics, the change process and the evolution mechanism of the microstructure. Considerable research has been conducted to obtain clad plate with high interface bond quality as well as excellent mechanical properties. The finite element method (FEM) was employed to simulate the co-deformation of different plates and determine the stresses and strains acting on the plates during the roll-cladding [6]. The deformation characteristics of double-layered plate during rolling were simulated by the finite element method, and the effects of process 
parameters on rolling were determined [7]. Vacuum hot-rolling experiments on composite plate were carried out and the temperature effect on microstructure, deformation behavior and mechanical properties of clad plates was analyzed [8]. The microstructure and deformation behavior were investigated using single-pass thickness reductions of 30, 50, and $60 \%$ of $\mathrm{Mg} / 3 \mathrm{Al} / 1 \mathrm{Zn}$ clad plate [9]. Multi-pass hot-rolling tests were carried out in a protective atmosphere. The deformation behavior of the interfacial components was investigated for different reduction ratios $[10,11]$. The microstructure of interfaces then was analyzed, and the mechanical properties were determined [12-14].

Type 304 stainless steel and HSLA low-alloy steel composite panels were prepared, and their bonding properties and mechanical properties were analyzed [15]. The deformation behavior of Q345R/304 clad plate was simulated, and the influence of process parameters on the rolling of double layer plate was assessed [16]. The microstructure and elemental distribution at the cladding interface were investigated, and the shear strength at the interface of the plate was measured [17]. Many researchers have reported that the rolling temperature and reduction rate were the main factors that affected the bonding interface and suitable corresponding rolling parameters were needed to improve the interface bonding of clad plates containing different materials.

In the present investigation, clad plates consisting of 316L stainless steel and Q345R plain carbon steel were analyzed. A thermomechanical microstructure simulation model was established using the DEFORM software. The interface bonding state was predicted according to interface bonding conditions. Each component of the stainless steel clad plate had excellent properties but the overall mechanical properties of the clad layer exceeded those of the base layer. Combined with the analysis of the change of grain size on the base layer, optimal rolling parameters can be formulated. The hot-rolling tests were carried out using post-rolling mechanical testing and microscopy, in order to confirm the optimal rolling parameters.

\section{Simulation of the Forming Process of Clad Plate.}

1.1. Rolling Model Establishment by DEFORM. To avoid the warping deformation during the rolling process of a clad plate, four symmetrical layers are stacked with two substrate layers (low alloy steel Q345R) on the outside and two cladding layers (stainless steel $316 \mathrm{~L}$ ) in the middle. The rollers are assumed to be rigid bodies to simplify the simulation of the process during hot-rolling. By using the tetrahedron meshing of DEFORM-3D, the substrate layer was divided into 6000 units, the cladding layer was divided into 38,000 units, and the roller was divided into 15,000 units. The interface was meshed with the same units, which reflects the actual rolling condition and the bonding state. The finite element model of reversible rolling is shown in Fig. 1.

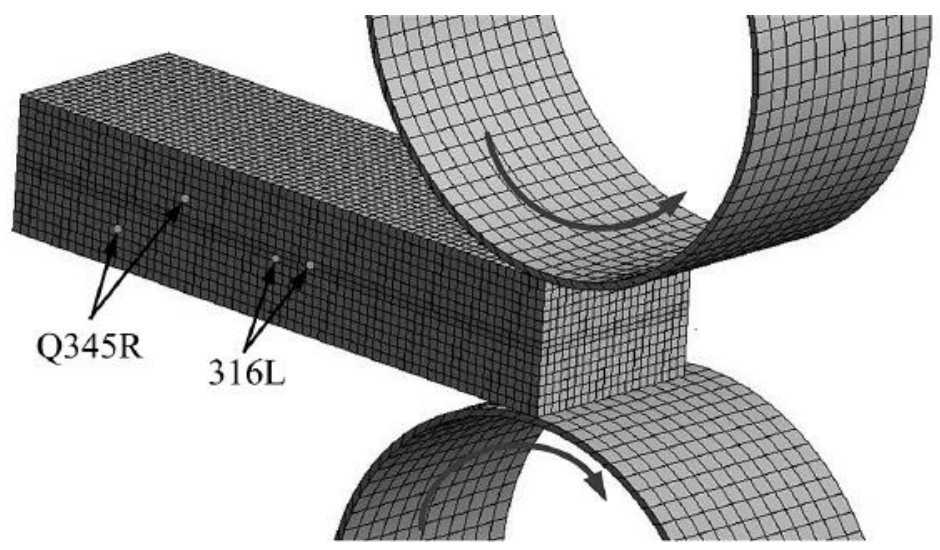

Fig. 1. Three-dimensional finite element model for stainless steel clad plate. 
The substrate of Q345R material and the cladding layer of 316L stainless were designed with the dimensions of $1000 \times 300 \times 90 \mathrm{~mm}$ and $1000 \times 300 \times 10 \mathrm{~mm}$, respectively. The initial thickness ratio was 1:9. The rolling speed was $1.5 \mathrm{~m} / \mathrm{s}$. The diameter of work roll was $\varnothing 750 \mathrm{~mm}$. Coulomb's friction model was applied to simulate contact between the roller and the slab and the friction coefficient was considered to be 0.3 . The friction type between the substrate and cladding layer was considered as shear friction with a friction coefficient of 0.5 . The contact heat transfer coefficient between the slab and the roll surface was set to be $40 \mathrm{~kW} /\left(\mathrm{m}^{2} \cdot{ }^{\circ} \mathrm{C}\right)$, the convective heat transfer coefficient between the free surface of the low alloy steel and the external environment was taken as $11 \mathrm{~W} /\left(\mathrm{m}^{2} \cdot{ }^{\circ} \mathrm{C}\right)$, and the radiative heat transfer coefficient was set to $18 \mathrm{~kW} /\left(\mathrm{m}^{2} \cdot{ }^{\circ} \mathrm{C}\right)$.

1.2. Setting of Rolling Temperature and Reduction. The stress-strain curves of the two materials at different temperatures are shown in Fig. 2. The plastic hot working temperature of the Q345R low alloy steel ranged from 900 to $1300^{\circ} \mathrm{C}$, while that of $316 \mathrm{~L}$ stainless steel ranged from 930 to $1280^{\circ} \mathrm{C}$. In order to study the effects of different rolling temperatures and reduction rates on the formability of the stainless steel clad plate, different rolling temperatures $\left(950,1050,1150\right.$, and $\left.1250^{\circ} \mathrm{C}\right)$ and cumulative reduction rates $(12.5$, $25,37.5,50,60,70$, and $75 \%$ ) were selected. After the multi-pass reversible rolling, the interface bond status of the stainless steel clad plate and the grain change law of the substrate layer were analyzed.

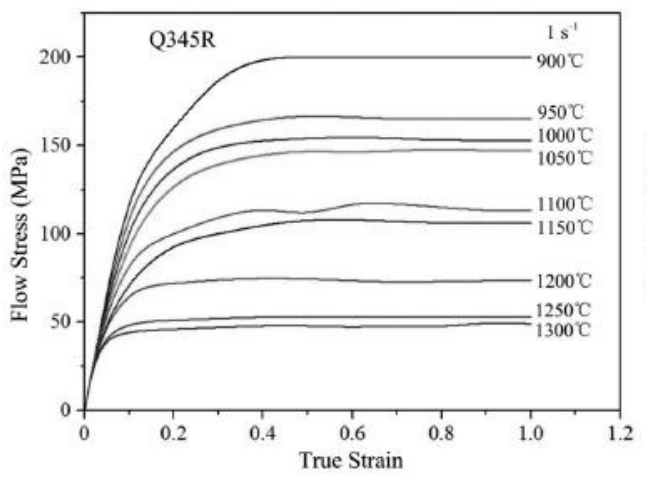

a

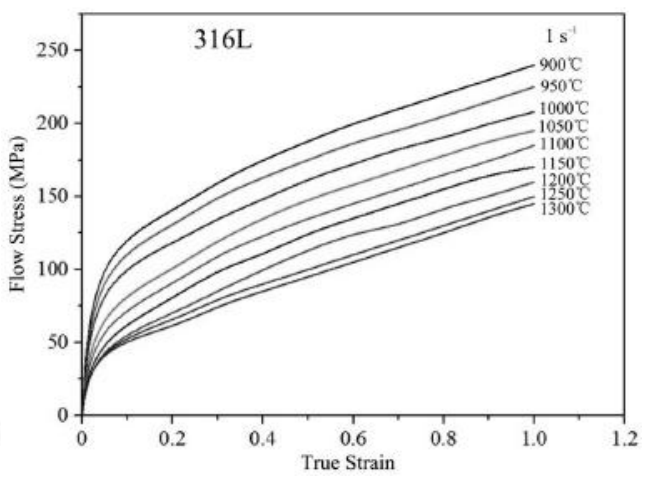

b

Fig. 2. Stress-strain curves at different temperature for Q345R (a) and 316L (b) steels.

2. Determination of Interface Bonding Status. According to the 'gap action' mechanism and membrane theory, the bonding of two metal panels is influenced by the rolling temperature, the reduction rate and other factors. Bonding of the surface atoms is caused by the breakdown of the interfacial oxide layer. In order to study the influence of different rolling temperatures and reduction rates on the bonding interface, the vertical stress of the cladding layer at the interface and the equivalent strain of the bimetallic layer were calculated. The bonding state of the interface can be determined according to conditions that interface bonding should meet: (i) the substrate and cladding layer are both in the plastic deformation state; (ii) the vertical stress of the interface is larger than the deformation resistance of the cladding layer; (iii) the difference in average strain between the substrate and cladding layer is less than 0.01 .

In DEFORM simulation post-processing, 8 nodes on the interface in the rolling deformation zone were selected from the symmetrical side of the clad plate to the outer side. The interface vertical stress of the cladding layer and the equivalent strain of the bimetallic layers were analyzed to determine that interface bonding state. 
2.1. Analysis of Vertical Stress at the Interface. The deformation resistance of the cladding layer decreased with increase in the rolling temperature. According to the stress-strain curve, and through an interpolation calculation, the deformation resistance of the clad plate was $108,81,67$, and $58 \mathrm{MPa}$ when the rolling temperature was 950,1050 , 1150 , and $1250^{\circ} \mathrm{C}$. When the vertical stress of the cladding layer exceeded the deformation resistance, the calculated results indicated that the bimetallic layers had generated a large degree of plastic deformation and the interface would bond to a certain degree. The vertical stress distribution on the interface in the deformation zone under four conditions of rolling temperature is shown in Fig. 3. The vertical stress of the interface increased with increase in the reduction rate and decreased with increase in temperature. The average values of vertical stress under different temperatures and reduction rates were calculated. When the rolling temperature was $950^{\circ} \mathrm{C}$ and the reduction rate was $70 \%$, the vertical stress was 118.5 $\mathrm{MPa}$, which was higher than the deformation resistance of $108 \mathrm{MPa}$, indicating that interfacial bonding would occur. Similarly, when the rolling temperature was $1050^{\circ} \mathrm{C}$ and the reduction rate was $60 \%$, the vertical stress was $93.8 \mathrm{MPa}$. When the rolling temperature was 1150 and $1250^{\circ} \mathrm{C}$, and the interface bonding reduction rate was $50 \%$, the vertical stress was 78.5 and $69.3 \mathrm{MPa}$, respectively.

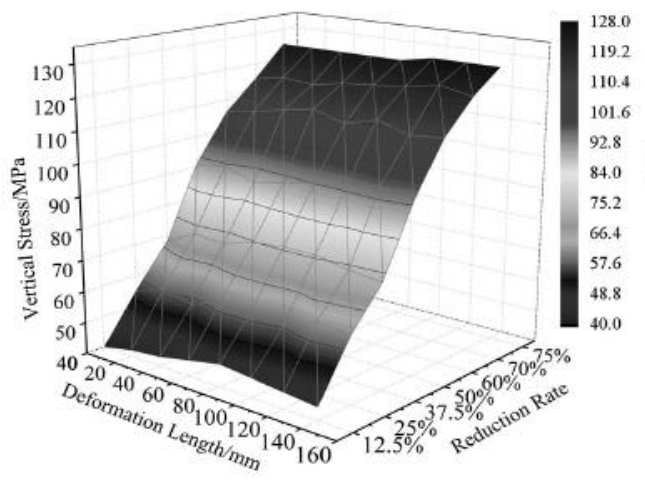

a

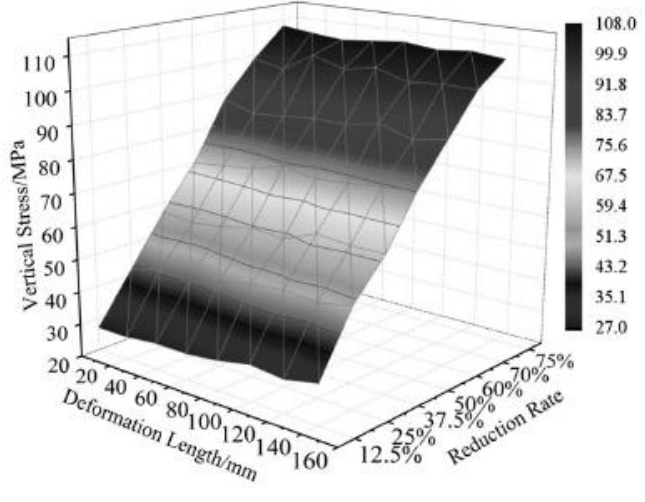

C

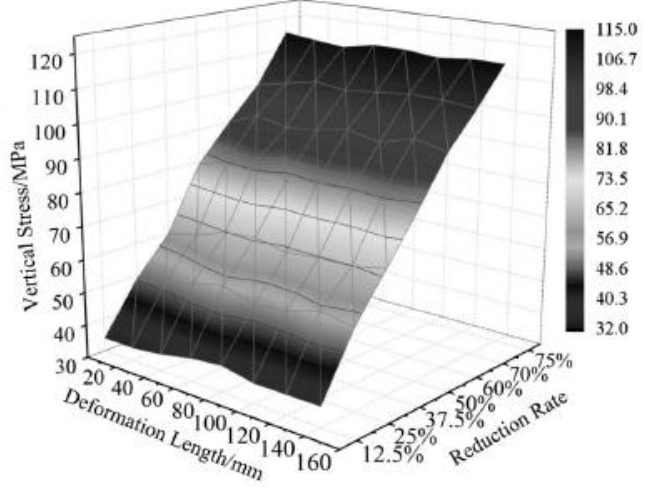

b

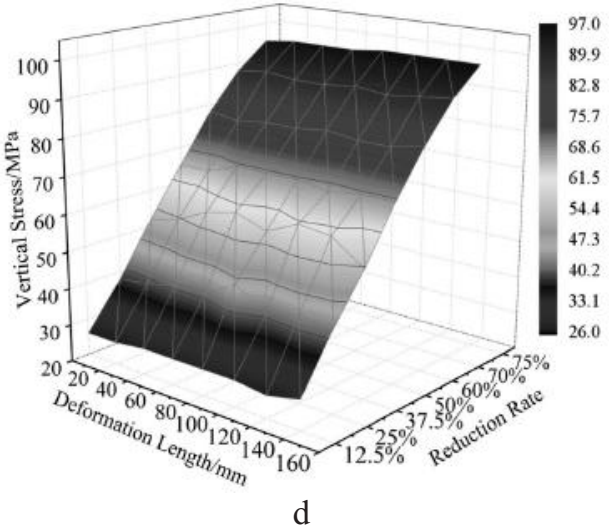

Fig. 3. Vertical stress distribution at the interface of different rolling temperature: (a) $950^{\circ} \mathrm{C}$; (b) $1050^{\circ} \mathrm{C}$; (c) $1150^{\circ} \mathrm{C}$; (d) $1250^{\circ} \mathrm{C}$.

2.2. Analysis of Equivalent Strain at the Interface. The effective bonding of stainless steel clad plate should not only meet the stress determination conditions but also should meet the deformation coordination requirements. During the rolling process, the difference of equivalent strain between the two metal interfaces in the deformation zone should be less 
than 0.01 . The equivalent strain distributions of the interface in the deformation zone at four conditions of rolling temperature are shown in Fig. 4. It was easier to generate plastic deformation in the substrate layer than in the cladding layer during the rolling process, owing to there being less deformation resistance in the substrate layer than the cladding layer. The equivalent strain difference between the two layers decreased with the increase in the reduction rate. When the rolling temperature was $950^{\circ} \mathrm{C}$ and reduction rate was $70 \%$, the equivalent strain difference was 0.0091 , i.e., less than 0.01 , which met the deformation compatibility requirements and implied the effective bonding of bimetallic interfaces (see Fig. 4a). When the rolling temperature was $1050^{\circ} \mathrm{C}$ and reduction rate was $60 \%$, the equivalent strain difference was 0.0085 , as shown in Fig. 4b. In Fig. 4c and 4d, when the rolling temperature was 1150 and $1250^{\circ} \mathrm{C}$ and reduction rate was $50 \%$, the equivalent strain difference was 0.0074 and 0.0082 , respectively. In the latter three conditions, the interface would also bond effectively.
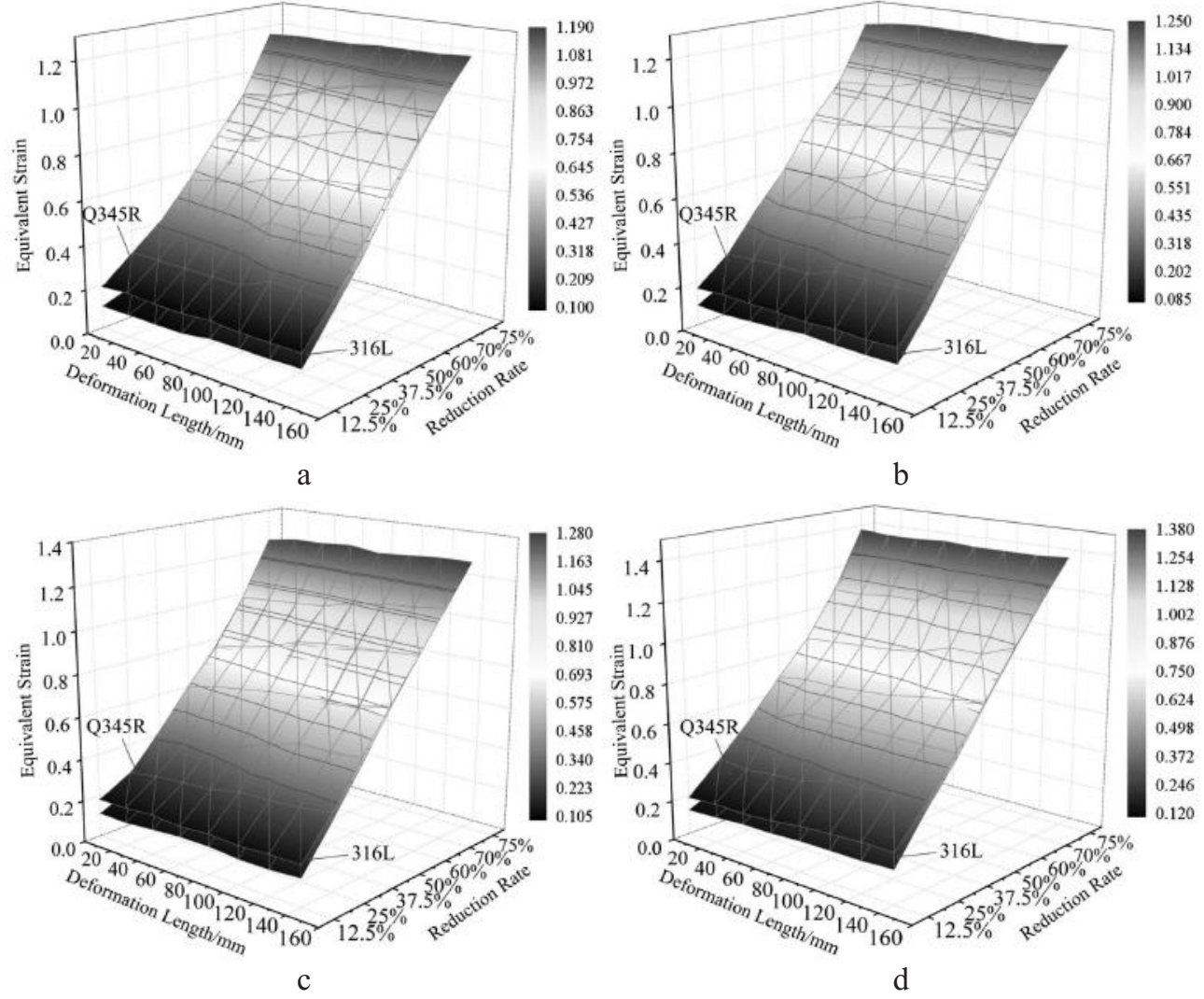

Fig. 4. Equivalent plastic strain distribution on the interface under different rolling temperatures: (a) $950^{\circ} \mathrm{C}$; (b) $1050^{\circ} \mathrm{C}$; (c) $1150^{\circ} \mathrm{C}$; (d) $1250^{\circ} \mathrm{C}$.

3. Grain Simulation of Stainless Steel Clad Plate. hot-rolling temperature is the main factor that affects the re-crystallization process of the clad plate. When the temperature is high, this enhances the dislocations and leads to dynamic re-crystallization. Simultaneously, grain boundary mobility increases and this greatly promotes re-crystallization nucleation and grain growth. However, too high a temperature will produce a coarser grain structure that detracts from the characteristics of the clad plate. The low alloy steel accounts for the larger proportion of the stainless steel clad plate and the effect of temperature on the grain size of stainless steel will directly determine the overall mechanical properties of clad plate. In this 
study, the size and distribution of grains in the low alloy steel Q345R after rolling was simulated using cellular automaton (CA) to investigate the effect of different rolling temperatures on grain size changes in the substrate layer.

\subsection{Establishment of CA Model.}

3.1.1. Dislocation Density Evolution Model. Work hardening and recovery softening behavior affects the thermoplastic deformation of the metal. On the one hand, the work hardening leads to an increase in dislocation density. On the other hand, the recovery softening caused by dynamic recovery and re-crystallization reduces the dislocation density. During this investigation, the evolution of the microstructure was analyzed based on the Laasroui-Jonas model [18]:

$$
\begin{aligned}
& d \rho_{i}=\left(h-r \rho_{i}\right) d \varepsilon, \\
& h=h_{0}\left(\frac{\dot{\varepsilon}}{\dot{\varepsilon}_{0}}\right)^{m} \exp \left(\frac{m Q}{R T}\right), \\
& r=r_{0}\left(\frac{\dot{\varepsilon}}{\dot{\varepsilon}_{0}}\right)^{-m} \exp \left(\frac{-m Q}{R T}\right),
\end{aligned}
$$

where $\rho_{i}$ is the dislocation density of cell, $r$ is the softening coefficient, $m$ is the strain rate sensitivity constant, $m=0.2, h$ is the hardening coefficient, $h_{0}$ and $r_{0}$ are the hardening constant and recovery constant, $\varepsilon, \dot{\varepsilon}$, and $\dot{\varepsilon}_{0}$ are the strain, strain rate, and strain rate calibration constant, respectively, $Q$ is the activation energy, $R$ is the gas constant, and $T$ is the blank temperature.

3.1.2. Recovery Model. The dislocation density of the material decreases during the process of dynamic recovery. The Goetz-Seetharaman dynamic recovery model [19] was adopted in the DEFORM software; that is, a certain amount of cell $N$ is selected arbitrarily for each time step and the dislocation density is reduced by half:

$$
\rho_{i, j}^{t}=\rho_{i, j}^{t-1} / 2
$$

The dislocation density of each cell is distributed unevenly. Value of $N$ is determined by the following equation:

$$
N=\left(\frac{\sqrt{2} M}{K}\right)^{2} \dot{\rho}^{2},
$$

where $M$ is the total cell number, $K$ is a constant, $K=6030$, and $\dot{\rho}$ is the change rate of the dislocation density.

3.1.3. Nucleation Model of Dynamic Re-crystallization. Dynamic re-crystallization nucleation is associated with the accumulation of dislocation density [20]. With increasing strain, the dislocation density of the substrate material increases at a certain rate. When the dislocation density reaches a certain critical value, the re-crystallized grains will begin to nucleate at a certain rate at the parent grain boundary, sub-grain boundary and at locations where there is a high dislocation density. The research shows that the nucleation rate $n$ is closely related to the strain rate $\dot{\varepsilon}$, and the relationship between nucleation rate $n$ and strain rate $\dot{\varepsilon}$ is linear:

$$
n=C \dot{\varepsilon}^{\alpha_{1}},
$$

where $C$ and $\alpha_{1}$ are constants, $C=200, \alpha_{1}=0.9$. 
3.1.4. Dynamic Re-crystallization Growth Model. The dislocation density difference between the parent grains and the dynamic re-crystallization grains is large because the dislocation density in the parent grains is high but the dislocation density in the new dynamic re-crystallization grains is almost zero, which provides the driving force for the growth of re-crystallization grains (i.e., the grain boundaries of low density dislocation grains move into the sides of high density dislocation grains). The relationships between the growth rate of the re-crystallized grains $v$, the mobility of the large angle grain boundaries $\eta$, and the driving force acting on the grain boundary $f$ can be written as

$$
\begin{gathered}
v=\eta f, \\
\eta=\frac{b d D_{0}}{k T} \exp \left(-\frac{Q_{b}}{R T}\right),
\end{gathered}
$$

where $b$ is the Burgers vector, $D_{0}$ is the grain boundary self-diffusion coefficient at absolute zero degrees, $Q_{b}$ is the grain boundary diffusion activation energy, and $k$ is the Boltzmann constant.

When the re-crystallization grains with radius $r$ grow, the driving force per unit area can be expressed as follows:

$$
\begin{gathered}
f=T \Delta \rho-\frac{2 Y}{r}, \\
Y=Y_{m} \frac{e}{e_{m}}\left(1-\ln \frac{e}{e_{m}}\right),
\end{gathered}
$$

where $\Delta \rho$ is the dislocation density difference between the newly formed grains and the parent grains, $Y$ is the interface energy, which depends on the orientation difference between two adjacent grains, $e$ is the orientation difference between the newly-formed grains and the adjacent grains, and $e_{m}$ and $Y_{m}$ are the orientation difference and grain boundary energy of large-angle grain boundaries, respectively.

3.2. CA Simulation Results and Discussion. The grain distribution of the substrate layer after rolling at a strain rate of $1 \mathrm{~s}^{-1}$ under different initial rolling temperatures of 950 , 1050,1150 , and $1250^{\circ} \mathrm{C}$ are shown in Fig. 5. Different colors indicate different grains and black lines represent grain boundaries. The grain size value was increased gradually with increase in the rolling temperature. When the rolling temperature was $950^{\circ} \mathrm{C}$, the average grain size was $3.4 \mu \mathrm{m}$; the grains were very small and were distributed unevenly, as shown in Fig. 5a. When the rolling temperature was $1050^{\circ} \mathrm{C}$, the average grain size was $4.5 \mu \mathrm{m}$, and the uneven distribution was improved, as shown in Fig. 5b. In Fig. 5c, the average grain size was $6.8 \mu \mathrm{m}$, the grain size is appropriate and it is well-distributed. This indicated that the mechanical properties of the stainless steel clad plate were improved. In Fig. $5 \mathrm{~d}$ it can be observed that the grains were coarse and distributed unevenly, with the average grain size of $8.5 \mu \mathrm{m}$, when the rolling temperature rose to $1250^{\circ} \mathrm{C}$. Through analysis of the interface bonding and the grain size simulation of Q345R/316L stainless steel composite plate it can be deduced that the higher the rolling temperature, the lower is the reduction rate. However, the excessive temperature will result in coarse and uneven grains. Considering the constraints of rolling mill capacity, roll strength and motor capacity, a primary rolling temperature of $1150^{\circ} \mathrm{C}$ was chosen and the cumulative rolling reduction was $50 \%$ for vacuum hot-rolling tests of stainless steel clad plate. In order to verify the optimized rolling parameters, the microstructure was analyzed and the mechanical properties were evaluated. 


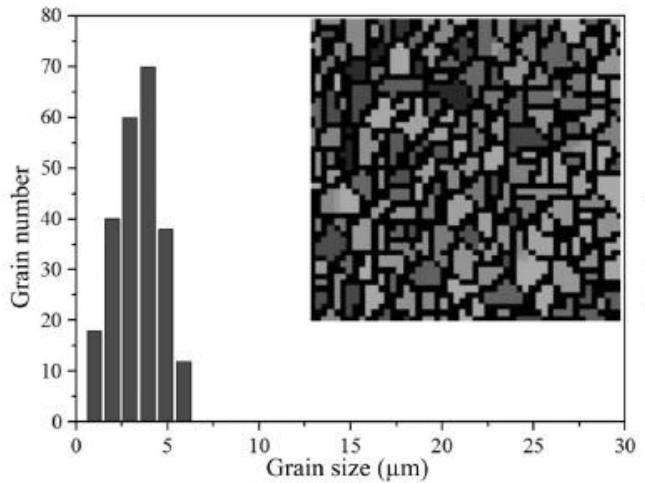

a

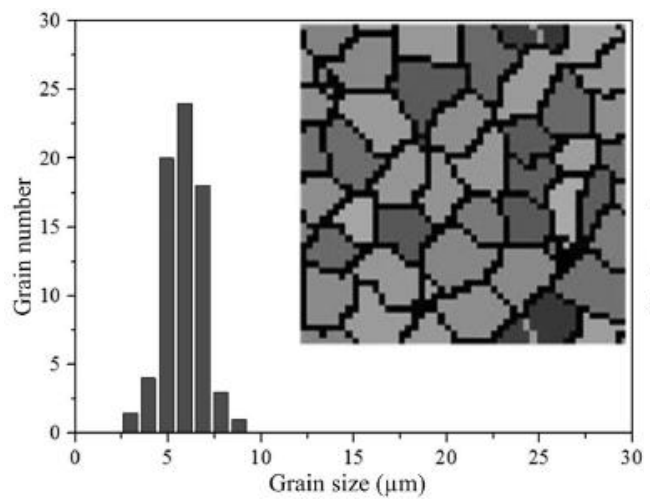

$\mathrm{c}$

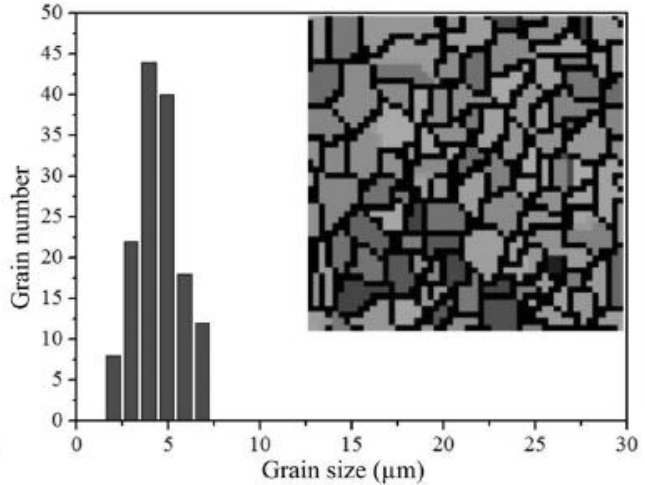

b

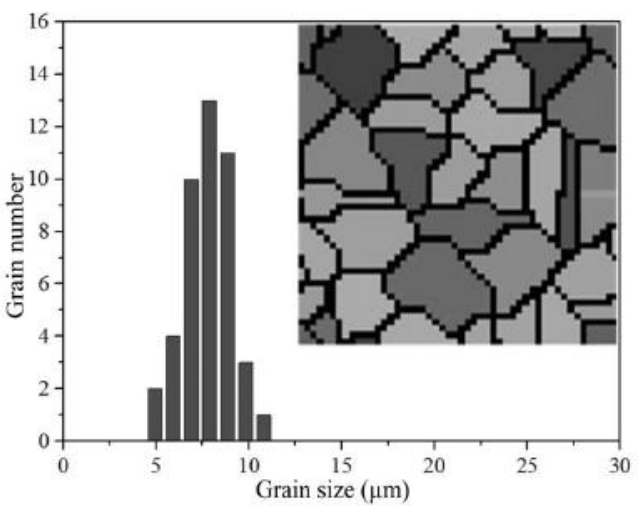

d

Fig. 5. Grain distribution of Q345R under different rolling temperatures: (a) $950^{\circ} \mathrm{C}$; (b) $1050^{\circ} \mathrm{C}$; (c) $1150^{\circ} \mathrm{C}$; (d) $1250^{\circ} \mathrm{C}$.

\section{Experimental.}

4.1. Experimental Procedure. The chemical compositions of the Q345R low alloy steel (substrate layer) and the 316L stainless steel (cladding layer) are given in Table 1. The substrate and cladding plates were designed with dimensions of $300 \times 300 \times 90 \mathrm{~mm}$ and $260 \times 260 \times 10 \mathrm{~mm}$, respectively. A thickness ratio of 1:9 was selected. Before roll bonding, the samples were assembled in the symmetrical mode, sealed by welding around, then vacuumed to $1 \cdot 10^{-1} \mathrm{~Pa}$. After the samples were heated to $1150^{\circ} \mathrm{C}$ and held for $2 \mathrm{~h}$, four pass rolling processes were performed with a rolling reduction $25 \mathrm{~mm}$ during each pass and with a cumulative reduction rate of $50 \%$. The final dimension of the samples was $800 \times 400 \times 50 \mathrm{~mm}$ by trimming, as shown in Fig. 6 .

$\mathrm{T}$ a b 1 e 1

Chemical Compositions of Stainless Steel Clad Plate (mass fraction /\%)

\begin{tabular}{|c|c|c|c|c|c|c|c|c|c||}
\hline Steel & $\mathrm{C}$ & $\mathrm{Si}$ & $\mathrm{Mh}$ & $\mathrm{P}$ & $\mathrm{S}$ & $\mathrm{Ni}$ & $\mathrm{Cr}$ & $\mathrm{Mo}$ & $\mathrm{Fe}$ \\
\hline Q345R & 0.150 & 0.35 & 1.40 & 0.020 & 0.010 & - & - & - & Bal. \\
\hline 316L & 0.016 & 0.51 & 1.11 & 0.022 & 0.001 & 10.11 & 16.32 & 2.06 & Bal. \\
\hline
\end{tabular}

After hot-rolling, the samples were air cooled to room temperature for the following experiments. Microstructure observation and element diffusion at the interface were carried 


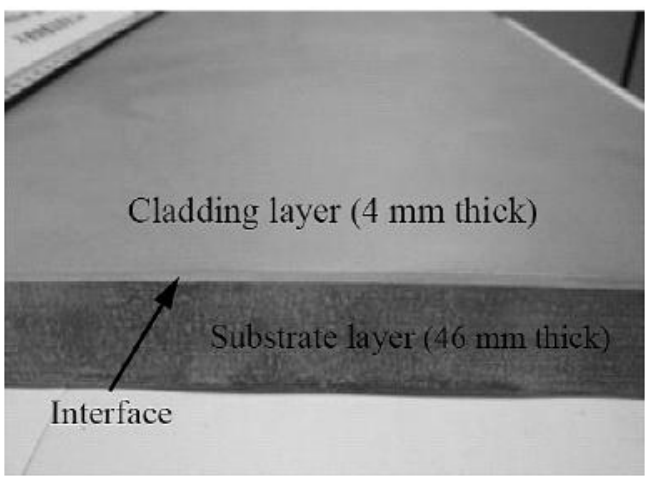

Fig. 6. Stainless steel clad plate sample.

out using scanning electron microscopy and EDS after corrosion on the cross section of samples. The hardness of the interface was measured using a Vickers hardness tester. Shear, tensile and cold bending tests were conducted in accordance with GB/T 8165-2008 [21].

\subsection{Results and Discussion.}

4.2.1. Microstructural Observation. The interfacial microstructure of the stainless steel clad plate is shown in Fig. 7a. On the right side of the photograph, the microstructure was low alloy steel Q345R, consisting of ferrite and pearlite. Near the interface, the microstructure was composed mainly of ferrite, indicating a tendency for decarburization to have occurred (The term is typically used in metallurgy, describing a reduction in the content of carbon in metals - usually steel). This was attributed to the fact that the $\mathrm{C}$ content of the Q345R $(0.15 \%)$ was higher than that of the 316L $(0.016 \%)$, and there was a large difference in $\mathrm{C}$ content between the Q345R and the $316 \mathrm{~L}$ that resulted in diffusion of the $\mathrm{C}$ from the Q345R to the $316 \mathrm{~L}$ at high temperature. The left side of the composite interface was stainless steel $316 \mathrm{~L}$, composed of single austenite. Some of the grains exhibited twinning and the grain boundary was clear. Figure $7 \mathrm{~b}$ shows the interface bonding state of the clad plate. The bonding interface with a width of about $5 \mu \mathrm{m}$ was clear and was without cracks or wrinkles, presenting an approximate straight-line interface, which indicated that good bonding had been achieved at the reduction rate of $50 \%$.

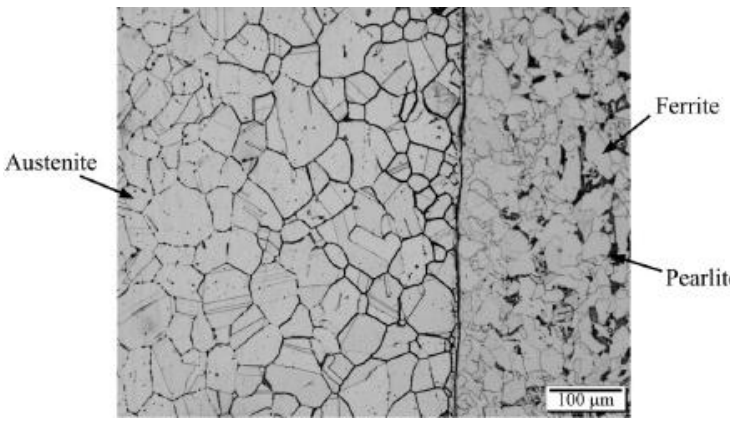

a

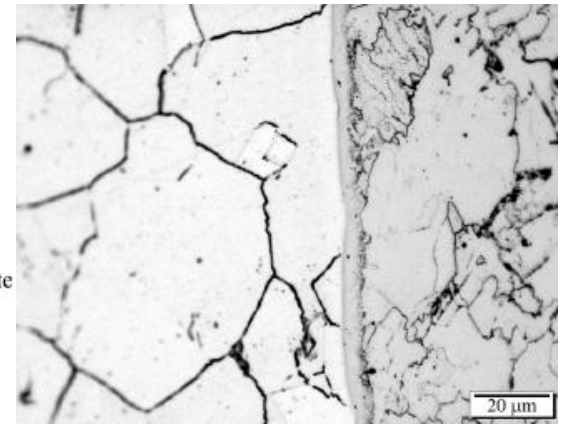

b

Fig. 7. The microstructure morphology of stainless steel clad plate: (a) metallographic structure analysis; (b) interface bonding state of clad plate.

4.2.2. Diffusion Analysis of Interface Elements. The linear scanning results of clad plate samples after hot-rolling are shown in Fig. 8. In Fig. 8a, different colors of spectral line show different elements: red for $\mathrm{C}$, green for $\mathrm{O}$, blue for $\mathrm{Cr}$, lake blue for $\mathrm{Fe}$, and 


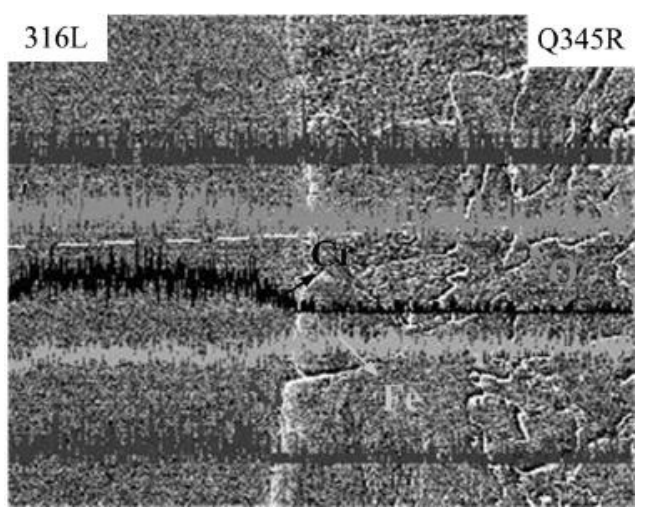

a

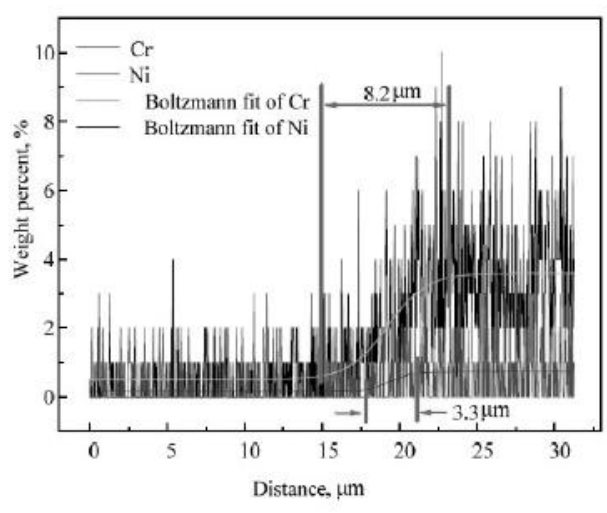

$\mathrm{b}$

Fig. 8. The linear scanning result of clad plate samples: (a) line scanning energy spectrum analysis; (b) interface element diffusion.

purple for Ni. It can be seen from Fig. 8a that the change in content of $\mathrm{C}, \mathrm{Fe}, \mathrm{O}$ on both sides of the interface were insignificant, while the contents of $\mathrm{Cr}$, $\mathrm{Ni}$ on either side of the interface changed significantly, indicating that the alloy elements of stainless steel diffused continuously at the interface into the low alloy steel side. Figure $8 \mathrm{~b}$ illustrates the element content changes of $\mathrm{Ni}$ and $\mathrm{Cr}$. The contents of $\mathrm{Cr}$ and $\mathrm{Ni}$ on stainless steel side was high and these elements diffused from interface into low alloy steel, which resulted in the enriched layer of $\mathrm{Cr}$ and $\mathrm{Ni}$ on the side of low alloy steel near the interface. The diffusion distance of $\mathrm{Cr}$ and $\mathrm{Ni}$ was 8.2 and $3.3 \mu \mathrm{m}$, respectively. This was because $\mathrm{Cr}$ had a larger concentration gradient, which led to a greater diffusion distance than that of the $\mathrm{Ni}$.

4.2.3. Hardness on Both Sides of Interface. The hardness distribution of the microstructure near the interface is illustrated in Fig. 9. As is evident, the average hardness of the 316L was $220 \mathrm{HV}$, which was consistent with the hardness of the stainless steel. The hardness of the interface was nearly $350 \mathrm{HV}$, due to the formation of carbide induced by the cross-diffusion of alloy elements and carbon near the interface. The average hardness of the Q345R was about $150 \mathrm{HV}$ in the decarburized zone at the interface. With increasing distance from the interface, the hardness of the Q345R increased gradually, until it was close to the hardness of substrate layer.

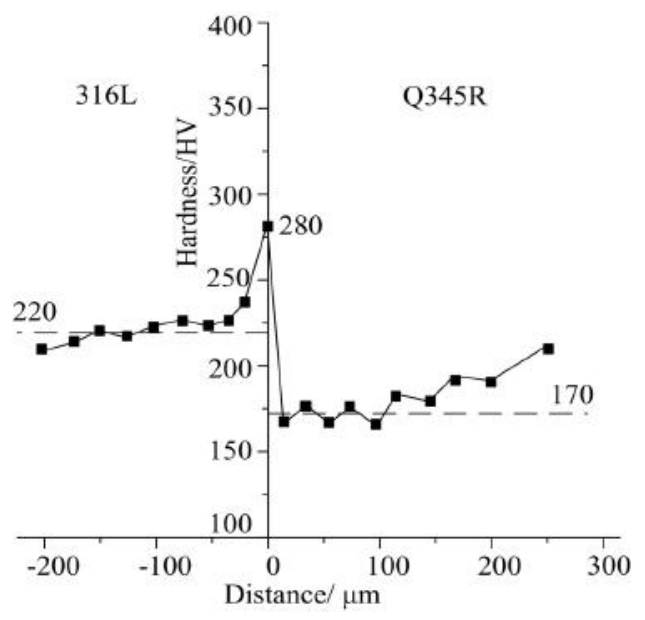

Fig. 9. Hardness distribution near the interface. 
Numerical Simulation and Experimental Study ...

$\mathrm{T}$ a b 1 e 2

Mechanical Properties of the Sample

\begin{tabular}{|c|c|c|c|c|}
\hline $\begin{array}{c}\text { Shear strength } \\
(\mathrm{MPa})\end{array}$ & $\begin{array}{c}\text { Yield strength } \\
(\mathrm{MPa})\end{array}$ & $\begin{array}{c}\text { Tensile strength } \\
(\mathrm{MPa})\end{array}$ & $\begin{array}{c}\text { Elongation } \\
(\%)\end{array}$ & $\begin{array}{c}\text { Impact energy } \\
(\mathrm{J})\end{array}$ \\
\hline 347 & 380 & 521 & 32.4 & 55 \\
\hline
\end{tabular}

4.2.4. Mechanical Properties. The shear, tensile and impact tests were carried out on the sample to evaluate the mechanical properties and the test results are summarized in Table 2. Shear strength is the key indicator to evaluate the mechanical properties of the clad plate. According to the GB/T8165-2008 [21], the shear strength of stainless steel clad plate should be greater than $210 \mathrm{MPa}$. However, in practical applications, in order to ensure good interface bonding, the bonding strength of clad plate should not be less than the shear strength of substrate, which was $300 \mathrm{MPa}$. After roll bonding, the shear strength of the sample was $347 \mathrm{MPa}$, which was higher than that of the substrate material, indicating good bonding of the interface. The yield strength of the clad plate was $380 \mathrm{MPa}$, which was higher than that of the substrate material $(345 \mathrm{MPa})$. The tensile strength was $521 \mathrm{MPa}$ which was higher than the lowest limit of tensile strength of the substrate material (510 MPa). The elongation was $32.4 \%$, which was much larger than the specified elongation of $21 \%$. The impact energy was $55 \mathrm{~J}$, which was larger than that of substrate material of $34 \mathrm{~J}$. Thus, in this investigation, the samples met the relevant mechanical properties of the Chinese Standards after hot-rolling.

\section{Con clusions}

1. A thermomechanical microstructure simulation model for stainless steel clad plate was established using 'DEFORM' software to model the interface bonding behavior of stainless steel clad plate and the microstructure of type Q345R carbon steel backing plate after hot-rolling. According to the rolling conditions, the bonding state of the interface can be modeled and the reduction rate needed for interface bonding was 70,60, and $50 \%$ and $50 \%$ when the rolling temperature was $950,1050,1150$, and $1250^{\circ} \mathrm{C}$. By simulation of the microstructure formation of the $\mathrm{Q} 345 \mathrm{R} / 316 \mathrm{~L}$ stainless steel clad plate after rolling, it was determined that when the rolling temperature was $1150^{\circ} \mathrm{C}$, the obtained grain size is uniform and the distribution is even. The model predicted that a rolling temperature of $1150^{\circ} \mathrm{C}$ and an accumulative reduction rate of $50 \%$ were the preliminary optimal roll processing parameters.

2. Based on the selected rolling process parameters, vacuum hot-rolling tests on Q345R/316L stainless steel clad plate were carried out. The interfacial microstructure, elemental diffusion, hardness and mechanical properties of the samples were tested and evaluated. The results showed that the microstructure of the carbon steel substrate layer after hot-rolling was composed mainly of ferrite and pearlite. The microstructure of the stainless steel cladding layer was composed of single austenite. In the adjacent domains of the interface, decarburization was evident on the low-alloy steel side. The composite interface bonded well and was approximately linearly distributed. The micro-hardness value of the interface after hot-rolling was high and the mechanical properties met the respective standard requirements.

3. By comparing the finite element simulation predictions with the test results, considering the effects of rolling temperature and reduction rate on the bonding properties of stainless steel clad plate at the rolling temperature of $1150^{\circ} \mathrm{C}$ and the cumulative rolling reduction exceeding 50\%, good interface bonding and excellent mechanical properties of stainless steel clad plate could be obtained. 
Acknowledgments. This project was supported by the Joint Fund for Iron and Steel Research of the National Natural Science Foundation of China and Baosteel Group Corporation (Grant No. U1660111), Science and Technology Research Foundation Project in Colleges and Universities of Hebei Province (Grant No. ZD2017076) and the Natural Science Foundation-Steel and Iron Foundation of Hebei Province (Grant No. E2014203118).

1. J. E. Lee, D. H. Bae, W. S. Chung, et al., "Effects of annealing on the mechanical and interface properties of stainless steel/aluminum/copper clad-metal sheets," J. Mater. Process. Tech., 187-188, 546-549 (2007).

2. L. Li, F. X. Yin, and K. Nagai, "Progress of laminated materials and clad steels production," Mater. Sci. Forum, 675-677, 439-447 (2011).

3. S. K. Zhang, H. Xiao, H. B. Xie, and L. C. Gu, "The preparation and property research of the stainless steel/iron scrap clad plate," J. Mater. Process. Tech., 214, No. 6, 1205-1210 (2014).

4. Z. Q. Mo, Y. Z. Liu, J. J. Geng,, and T. Wang, "The effects of temperatures on microstructure evolution and mechanical properties of $\mathrm{B}_{4} \mathrm{C}-\mathrm{AA} 2024$ composite strips prepared by semi-solid powder rolling," Mat. Sci. Eng. A, 652, 305-314 (2016).

5. J. Kamran, U. D. Shamas, N. H. Tariq, et al., "The beneficial effect of Ag in addition on deformation behavior, microstructure and texture in $\mathrm{Mg}-\mathrm{Al}-\mathrm{Zn}$ alloy during single pass warm rolling," Mater. Design, 81, 11-20 (2015).

6. J. Dong, C. Wu, Y. H. Pang, and X. Y. Liu, "Finite element simulation of Q235/304 carbon steel stainless steel clad sheet interface combination," Spec. Steel, 29, 36-38 (2008).

7. H. G. Kang, J. K. Kim, M. Y. Huh, and O. Engler, "A combined texture and FEM study of strain states during roll-cladding of five-ply stainless steel/aluminum composites," Mat. Sci. Eng. A, 452-453, 347-358 (2007).

8. Y. Y. Li, X. P. Zheng, W. W. Zhang, and Z. Q. Luo, "Effect of deformation temperature on microstructures and properties of 7075/6009 alloy," T. Nonferr. Metal. Soc., 19, 1037-1043 (2009).

9. Q. Qin, D. T. Zhang, Y. Zang, and B. Guan, "A simulation study on the multi-pass rolling bond of 316L/Q345R stainless clad plate," Adv. Mech. Eng., 7, 1-13 (2015).

10. K. S. Lee, S. E. Lee, H. K. Sung, et al., "Influence of reduction ratio on the interface microstructure and mechanical properties of roll-bonded Al/Cu sheets," Mat. Sci. Eng. A, 583, 177-181 (2013).

11. Y. Jing, Y. Qin, X. M. Zang, and Y. H. Li, "The bonding properties and interfacial morphologies of clad plate prepared by multiple passes hot-rolling in a protective atmosphere," J. Mater. Process. Tech., 214, No. 8, 1686-1695 (2014).

12. Q. X. Huang, X. R. Yang, L. F. Ma, et al., "Interface-correlated characteristics of stainless steel/carbon steel plate fabricated by AAWIV and hot-rolling," J. Iron Steel Res. Int., 21, No. 10, 931-937 (2014).

13. S. Y. Jiao, J. X. Dong, M. C. Zhang, and L. Zheng, "Influencing factors and bonding mechanism of hot-rolling bonded bimetals," Mater. Rev., 23, 59-62 (2009).

14. Z. Y. Jin and Z. C. Cui, "The effect of deformation temperature on dynamic re-crystallization," J. Yangzhou Univ. (Nat. Sci. Ed.), 14, 60-64 (2011).

15. G. M. Xie, Z. A. Luo, and G. L. Wang, "Interface characteristic and properties of stainless steel/HSLA steel clad plate by vacuum rolling cladding," Mater. Trans., 52, 1709-1712 (2011). 
16. W. C. Jiang, Z. B. Liu, J. M. Gong, and S. T. Tu, "Numerical simulation to study the effect of repair width on residual stresses of a stainless steel clad plate," Int. J. Pres. Ves. Pip., 87, 457-463 (2010).

17. X. B. Guo, Y. He, X. J. Zhang, and M. N. Li, "Microstructure and mechanical properties of binding interface between hot-rolled stainless steel/carbon steel clad plates," CFHI Tech., 5, 52-55 (2015).

18. S. Gourdet and F. Montheillet, "A model of continuous dynamic re-crystallization," Acta Mater., 51, No. 9, 2685-2699 (2003).

19. R. L. Goetz and V. Seetharaman, "Static re-crystallization kinetics with homogeneous and heterogeneous nucleation using a cellular automata model," Metall. Mater. Trans. A, 29, No. 9, 2307-2321 (1998).

20. D. L. Ouyang, S. Q. Lu, X. Cui, et al., "Dynamic re-crystallization of titanium alloy TA15 during $\beta$ hot process at different strain rates," Rare Metal. Mater. Eng., 40, 325-330 (2011).

21. GB/T 8165-2008. Stainless Steel Clad Plates Sheets and Strips, Chinese Standard, Implemented on May 1, 2009.

Received 15. 09. 2017 